\title{
A wearable sales assistant: capturing dynamic nonverbal communication behaviors using sensor technology
}

\author{
Sandra Pauser ${ }^{1}$ (D) $\cdot$ Udo Wagner $^{1}$
}

Published online: 19 March 2019

(C) The Author(s) 2019

\begin{abstract}
Sales research has focused on enhancing selling effectiveness and performance, which largely depends on the abilities and capabilities of the sales force. Interpersonal skills consisting of verbal and nonverbal communication have been identified as a main predictor of sales performance. However, sales researchers face the difficulty of measuring and tracking nonverbal behaviors, since these messages are perceived and processed mainly unconsciously. This field study applies a novel data-collection method in sales research to automatically track nonverbal communication behaviors (i.e., kinesics, paralanguage, and proxemics) of both, the salesperson and the customer, through wearable electronic devices, sociometric badges. The findings indicate positive effects of dynamic (versus restricted/static) nonverbal cues on a salesperson's charismatic appearance, which, in turn, yields favorable customer responses and sales performance.
\end{abstract}

Keywords Sociometric badges $\cdot$ Nonverbal behaviors $\cdot$ Dynamic nonverbal cues $\cdot$ Personal selling $\cdot$ Charisma

\section{Introduction}

For decades, sales research has focused on the enhancement of selling effectiveness and performance; selling effectiveness and performance, in turn, largely depend on the abilities and capabilities of the sales force. Correspondingly, the

Sandra Pauser

sandra.pauser@univie.ac.at

Udo Wagner

udo.wagner@univie.ac.at

1 Faculty of Business, Economics and Statistics, University of Vienna, Oskar-Morgenstern-Platz 1, 1090 Vienna, Austria 
identification of sales behaviors that drive performance has received significant attention in research (Leigh and Summers 2002). Among other factors, interpersonal skills, consisting of verbal and nonverbal communication, have been identified as a main predictor of sales performance (Rentz et al. 2002). Recent research findings confirm that a salesforce's nonverbal communication influences both customers' perceptions of the salespersons and the products/services at stake and sales performance (Leigh and Summers 2002). At the same time, however, there is a general consensus in the literature that such nonverbal cues are difficult to measure, as these messages are "encoded and decoded unconsciously" (Stewart, Hecker, and Graham 1987, p. 305), and thus, conventional marketing research methods are not very effective; state of the art sales researchers have mostly relied on observational data on nonverbal cues, which are subjective and can suffer from observation bias (Olguin-Olguin and Pentland 2008). This study presents a novel data-collection method to automatically detect nonverbal communication behaviors of the salesperson and the customer and thereby provides a noteworthy contribution to sales research.

Following the call for a more objective measurement of nonverbal behaviors by Olguin-Olguin and Pentland (2008), this research utilizes sociometric badges for data collection. These wearable electronic devices are capable of measuring "the amount of face-to-face interaction, conversational dynamics, physical proximity to other people, and physical activity levels" (Olguin-Olguin and Pentland 2008, p. 1). These authors provide application scenarios and recommend researchers to investigate "individual and global sales performance in retail stores and give advice on how to make interaction with clients more effective" (Olguin-Olguin et al. 2006, p. 3).

Accordingly, our empirical field study makes use of this objective datacollection method in a personal sales context (i.e., both, the salesperson and the customer wear sociometric badges during their sales interaction). Thus, we show that sociometric badges can be employed reliably and conveniently for sales research and demonstrate that they have predictive validity. We thereby contribute to the sales literature in three ways. Firstly, we provide a classification of nonverbal sales behaviors of different salespeople by objectively recording their nonverbal behaviors during a sales conversation in the field. Secondly, we relate these nonverbal cues to salespersons' perceived charisma and customer responses. We focus on charisma for two reasons: (i) it is a quality which has been ascribed to successful sales executives who have mastered their nonverbal behaviors (Fatt 1998); (ii) it has received relatively little attention in marketing thus far. Thirdly, we reveal various managerial implications for sales executives and offer guidance on how to improve their charismatic appearance, which in turn enhances customer responses and sales performance.

The subsequent section provides a literature review on the effects of a salesperson's nonverbal communication on perceptions of charisma and customer's response variables. Based on the literature, we frame a conceptual model including three hypotheses. The next section explains the design of the field study conducted on jewelry sales and presents the measurement capabilities of the novel technology. Statistical investigations test the hypothesized relationships between nonverbal communication and customer responses. A summary and suggestions for further research in the sales discipline conclude this paper. 


\section{Literature review}

\subsection{The importance of nonverbal communication in sales}

Marketing scholars provide substantial support for the effectiveness of nonverbal communication in personal selling (Stewart, Hecker, and Graham 1987). In general, nonverbal communication is defined as any communication that cannot be expressed with words (Leigh and Summers 2002). It comprises elements such as body movements, gestures, mimicry, eye contact, proximity, and posture, as well as vocal characteristics such as volume, voice tone, speed, and rhythm. Nonverbal cues can be classified into three categories: kinesics, paralanguage, and proxemics. Kinesics refers to the study of body movements including gestures and eye movement, whereas paralanguage studies voice characteristics such as volume or pitch (Williams, Spiro, and Fine 1990). The third category of nonverbal behaviors refers to proxemics, which denotes the study of distances between communicators (Williams et al. 1990).

Research findings indicate that "nonverbal communication in a service encounter dramatically impacts on the customer's evaluation of the service event" (Gabbott and Hogg 2000, p. 394). Furthermore, nonverbal cues provide valuable information about the respective counterpart. The nonverbal cues of the salesforce (e.g., loudness, pitch, voice quality, eye contact, gesturing) influence approachability variables including likability, credibility, attractiveness, and responsiveness (Burgoon, Birk, and Pfau 1990; Leigh and Summers 2002). Specifically, the literature points to the fact that dynamic communicators have a "dramatic, memorable, and attention-grabbing communication style that is immediate, expressive, and energetic" (Guerrero and Floyd 2006, p. 156). Dynamism is conveyed through various kinesic cues such as fluid and vigorous movements and an erect posture (Bettinghaus and Cody 1994). Paralinguistically, dynamism is associated with a moderately loud, rapid, expressive, and fluent voice (Apple, Streeter and Krauss 1979) that enhances a speakers' competency-based assessment (Burgoon et al. 1990).

To theoretically justify the relationship between nonverbal cues and customer responses, we draw on William et al.'s (1990, p. 29) salesperson-customer interaction framework, "which focuses on communication as the essence of the interaction." This framework builds on earlier work by Mehrabian (1969), which considers the interaction as a stimulus-response model in the sense that the addressee forms perceptions and attitudes based on the sender's nonverbal cues.

\subsection{The effects of nonverbal communication on perceptions of charisma}

Nonverbal cues enhance buyers' perceptions of the salesperson (Leigh and Summers 2002). Likewise, scholars in other disciplines point to the effectiveness of nonverbal communication in yielding favorable perceptions of charisma (Kirkpatrick and Locke 1996), which, in turn, produces advantageous performance outcomes (Antonakis, Fenley, and Liechti 2011). Charisma is considered to be a predominant quality of successful sales executives who master their nonverbal behaviors (Fatt 1998). Charismatic personalities possess the ability to articulate themselves through voice characteristics, body movements, and facial expressions that inspire others (Antonakis et al. 2011). Heide (2013, p. 305) defines 
charismatic nonverbal communication as "the ability to modulate nonverbal behavior to enhance client engagement".

Specifically, research in management, leadership, and politics points to the strong association between a dynamic communication style and perceptions of charisma (i.e., Antonakis et al. 2011). Holladay and Coombs (1994), for example, trained a confederate to manipulate his/her charismatic communication style experimentally to study its effect on perceptions of charisma and outcome variables. Paralinguistically, the charisma condition employs captivating and engaging tone of voice with vocal variety. Moreover, animated body movements (i.e., gestures and forward lean) and facial expressiveness also form part of the manipulation. Results reveal that the dynamic communication style (as opposed to the monotone and less active operationalization) serves as a significant predictor of perceived charisma (Holladay and Coombs 1994).

Given the strong linkage between dynamic nonverbal cues and perceptions of charisma, we hypothesize that:

H1: A dynamic communication style of the salesperson (as opposed to a restricted/ static style in terms of kinesics, paralanguage, and proxemics) will positively affect buyers' perceptions of the salesperson's charisma.

\subsection{The effects of nonverbal communication on customer responses}

Nonverbal communication behaviors do not only influence perceptions of salespeople, but also affect customer responses such as approachability and responsiveness variables (Leigh and Summers 2002). In addition, nonverbal communication is related to sales effectiveness. Peterson (2005) underlines the importance of nonverbal communication in sales by experimentally demonstrating that individuals trained in nonverbal communication increase customers' willingness to purchase.

Likewise, scholars find that a communicator's persuasiveness is enhanced by "increasing degrees of eye contact; smaller reclining angles; increasing rates of head nodding, gesticulation, and facial activity; increasing degrees of speech rate, speech volume, intonation, and unhalting quality of speech" (Mehrabian and Williams 1969, p. 42). In a similar vein, Leigh and Summers (2002) confirm that speech hesitations are negatively related to buyer's perceptions of the sales presentation (i.e., they are rated as less interesting and less persuasive). In their experimental study, Burgoon et al. (1990) identify greater vocal variety to be associated with competence. Peterson, Cannito, and Brown (1995, p. 13) point to the effectiveness of varying levels of loudness and speakers perceived attractiveness. They further note that "voice characteristics correlated highly with output sales performance".

Moreover, proximity yields enhanced ratings of persuasiveness and eye contact shows significant effects only at larger distances (Mehrabian and Williams 1969). Empirical studies reveal that eye gaze boosts sales presentation, believability, and emotionality (Leigh and Summers 2002). Dependent on the cultural setting, negative attitudes are inferred if the interactions occur at too far or too close distances (Hall and Hall 1977). 
In sum, prior research confirms the effectiveness of a dynamic communication style in sales as opposed to a rather static, monotone, and hesitated sales presentation with little vocal variety (i.e., volume). Thus, we hypothesize that:

H2: A dynamic communication style of the salesperson (as opposed to a restricted/ static style in terms of kinesics, paralanguage, and proxemics) will positively affect customer responses.

\subsection{The relationship between nonverbal communication, perceived charisma, and customer responses}

Nonverbal cues serve as a key determinant of a person's charisma. Experimental research shows that manipulating nonverbal communication behaviors by means of enhanced body movement and animated voice tone and facial expressions enhances perceptions of charisma (Kirkpatrick and Locke 1996). Moreover, individuals who are perceived as more charismatic are better able to exhibit influence over their conversational partner (Vercic and Vercic 2011). Given their appeal, individuals who are perceived as more charismatic gain more attention and are more likable (Heide 2013), which in turn most likely leads to approachability behaviors. Customers' attraction to salespeople who they perceive as charismatic may also increase their attitude toward the salesperson (Pauser, Wagner and Ebster 2018). Sy, Choi, and Johnson (2013) confirm this mediating role of perceived charisma between nonverbal communication and outcome variables in a leadership context. In line with this finding, we postulate that nonverbal communication behaviors influence perceptions of a salesperson's charisma and we expect those perceptions to enhance customer responses such as attitudes and buying behaviors. Thus, we hypothesize that:

H3: A salesperson's perceived charisma mediates the relationship between a salesperson's dynamic communication style (as opposed to a restricted/static style in terms of kinesics, paralanguage, and proxemics) and customer responses.

Figure 1 presents the research hypotheses schematically.

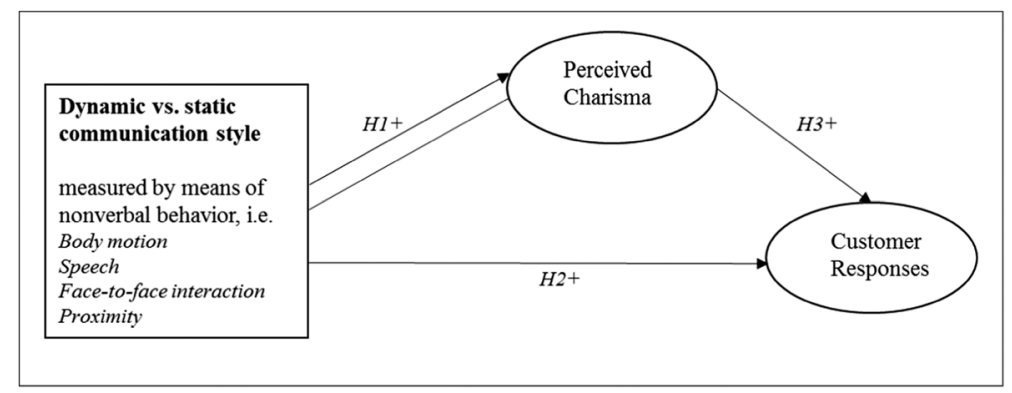

Fig. 1 Conceptual model 


\section{Empirical study}

\subsection{Research design and sample characteristics}

Our empirical research is descriptive in nature. A field study was carried out over a period of 3 months in a Central European country by one of the authors, who approached various jewelry stores (from fashion-jewelry stores to high-end luxury stores) by means of cold canvassing. The reasons for the selection of jewelry sales are manifold: more complex and expensive products result in greater importance of the personal selling, which, in turn, requires greater explanation and consultancy. Since jewelries are typically not self-service products, a client must engage in a personal selling interaction. The stores ranged from small jewelry designers to luxurious international chains to cover a wide spectrum of different salespeople.

After the store managers provided their approval, the salespersons and potential clients were instructed to both wear a sociometric badge during their personal selling situation. To protect the participants' privacy, the literal content of the sales conversation was not recorded. After the sales conversation, both parties completed a survey and provided some demographic data. The sample comprises 32 different dyads (consisting of 32 different salespeople and 32 different customers). The salespersons' ages ranged from 21 to 56, with a mean of 34 years. Furthermore, 63\% were female. The clients' ages ranged from 18 to 71 , with a mean of 36 years; $75 \%$ were female. The sales conversation lasted on average $8.5 \mathrm{~min}$. After completing the survey, study participants were debriefed about the purpose of the study.

\subsection{Measurement}

\subsubsection{Measurement of nonverbal behaviors}

Various methods exist to measure nonverbal behaviors. One commonly used approach codes specific behaviors manually based on an existing coding scheme; however, this approach is very time-consuming. Technological advances provide alternatives such as sensors, full body motion tracking systems, and eye trackers. Their applications, however, are primarily suited to laboratory-based settings. Quite recently, a wearable sensor package (sociometric badge) was developed, which "offers clear advantages over traditional methods since data is automatically collected by electronic sensors rather than humans" (Olguin-Olguin and Pentland 2008, p. 1).

To incorporate an innovative feature, this research utilizes these social sensors (infrared sensor, microphone, Bluetooth module, 3-axis accelerometer) for automatic data collection, which allows data to be exported in a spreadsheet format. Sociometric badges are similar in size to mobile phones and almost imperceptible for the user (Kim et al. 2012). They are small, unobtrusive, worn around the neck, and record data classified into several categories (i.e., body motion, speech, face-to-face interaction, and proximity). Each of these categories contains a number of different variables. In line with Olguin-Olguin, Gloor, and Pentland (2009), we focus on kinesics (variables: (a) posture activity, (b) posture (front/back), (c) posture (sideward lean left/right)), paralanguage (variables: (d) volume, (e) volume consistency, (f) pitch), and proxemics (variables: (g) total time of face-to-face interaction, and $(\mathrm{h})$ total time of close 
proximity). The measurement units of the behavioral variables refer to technical details and not all of them are intuitively interpretable. Therefore, transformations are carried out for presentational convenience. Table 1 provides an overview of these variables and their interpretation. ${ }^{1}$

\subsubsection{Measurement of customer responses}

We focus on a broad spectrum of customer response variables that are well-established in the sales and marketing literature including customers' evaluations of salespeople (attitude), the product they promote (perceived product quality), liking of the store (intention to recommend), and actual purchase (yes/no). The charisma of the salesperson was measured on the nine-item scale by Khatri, Ng, and Lee (2001). The 7-point scales (with $1=$ no approval and 7=full approval) measuring attitude toward the salesperson (MacKenzie and Lutz 1989), perceived product quality (Grewal, Monroe, and Krishnan 1998), and intention to recommend the store (Maxham and Netemeyer 2002) comprised three items each. All scales show satisfactory psychometric properties (Cronbach's $\alpha$ above .9).

\subsection{Results}

\subsubsection{Classification of nonverbal behaviors}

Our hypotheses tried to simplify the research agenda by distinguishing between dynamic vs. static communication styles. Thus, as a first step, our analysis aims to classify salespeople based on their nonverbal messages. For classification purposes, hierarchical cluster analysis was conducted. Prior to the analysis, we performed a $z$-transformation on all nonverbal variables. We used Ward's fusion criterion with squared Euclidean distance as a measure of dissimilarity to determine the number of clusters. The corresponding dendrogram suggested a two-cluster solution. A $k$-means cluster analysis finetuned this solution, as Table 2 (upper panel) presents the results. Entries in columns 2, 3, and 4 show averages per sample/cluster. To make these entries more easily interpreted, nonverbal behavioral variables have been transformed such that their domain falls between zero and one. ${ }^{2}$ For descriptive purposes, the rightmost column of Table 2 provides $p$ levels of a Kruskal Wallis test. ${ }^{3}$ Two steps investigated and confirmed the reliability of the cluster solution: (a) split-sample (of salespeople) analysis of two randomly determined subsamples; (b) split-half (of nonverbal variables) analysis.

Analyzing the salespersons' nonverbal cues, we conclude that salespeople belonging to cluster 1, labeled as "dynamic actives", demonstrate enhanced posture activity and animated voice tone by varying their tone of voice in terms of loudness. In general, they speak louder than representatives of cluster 2 and show a higher pitch rate. This might be explained by the fact that this cluster is dominated by females, who generally speak on a higher frequency range than males (Peterson et al. 1995). Furthermore,

\footnotetext{
${ }^{1}$ Olguin-Olguin et al. (2009) provide a more detailed elaboration on these variables.

${ }^{2}$ We refer to Table 1 for an intuitive interpretation of these variables

${ }^{3}$ We are aware that caution should be used when employing the same data for clustering and testing; we use a nonparametric statistic to account for the rather small cluster sizes
} 
Table 1 Nonverbal behavioral variables measured by the sociometric badge

\begin{tabular}{|c|c|c|}
\hline Category/technology & Variables of interest/intuitive interpretation & $\begin{array}{l}\text { Technical } \\
\text { specifications }\end{array}$ \\
\hline \multirow[t]{3}{*}{$\begin{array}{l}\text { Body motion } \\
\quad(3 \text {-axis accelerometer) }\end{array}$} & $\begin{array}{l}\text { (a) Posture activity } \\
\text { Small values indicate less posture activity } \\
\text { (high values indicate high posture activity) }\end{array}$ & \multirow[t]{3}{*}{$\begin{array}{l}\text { Mean energy of } \\
\text { accelerometer signal }\end{array}$} \\
\hline & $\begin{array}{l}\text { (b) Posture (front/back) } \\
\text { Small values indicate more forward lean } \\
\text { (high values indicate upright position) }\end{array}$ & \\
\hline & $\begin{array}{l}\text { (c) Posture (left/right) } \\
\text { Small values indicate upright position } \\
\text { (high values indicate sideward lean) }\end{array}$ & \\
\hline \multirow[t]{3}{*}{ Speech (microphone) } & $\begin{array}{l}\text { (d) Volume } \\
\text { Small values indicate low volume } \\
\text { (higher values indicate high volume) }\end{array}$ & Volume speech amplitude \\
\hline & $\begin{array}{l}\text { (e) Volume consistency } \\
\text { Small values indicate a variation in loudness } \\
\text { (high values indicate no variation in loudness) }\end{array}$ & Standard deviation \\
\hline & $\begin{array}{l}\text { (f) Pitch } \\
\text { Small values indicate a low pitch frequency } \\
\text { (high values indicate a high pitch frequency) }\end{array}$ & Pitch frequency \\
\hline $\begin{array}{l}\text { Face-to-face interaction } \\
\quad \text { (infrared sensor) }\end{array}$ & $\begin{array}{l}\text { (g) Total time of face-to-face interaction } \\
\text { Small values indicate less time of face-to-face } \\
\text { interaction (high values indicate more time } \\
\text { of face-to-face interaction) }\end{array}$ & $\begin{array}{l}\text { Badge is facing the other badge } \\
\text { within a } 30 \text {-degree cone and } \\
6 \text {-ft distance }\end{array}$ \\
\hline $\begin{array}{l}\text { Proximity } \\
\text { (Bluetooth module) }\end{array}$ & $\begin{array}{l}\text { (h) total time of close proximity } \\
\text { Small values indicate less time of close } \\
\text { proximity (high values indicate more time } \\
\text { of close proximity) }\end{array}$ & $\begin{array}{l}\text { Badge is in close proximity } \\
\text { to the other badge } \\
\text { (less than } 1 \mathrm{~m} \text { ) }\end{array}$ \\
\hline
\end{tabular}

representatives of cluster 1 are more oriented toward the client (i.e., forward lean). As pointed out by Arena, Pentland, and Price (2010), higher activity levels are indicative of a person's excitement, whereas lethargic activity levels refer to disengagement.

On the contrary, representatives of cluster 2 are very static in their movement behaviors and do not vary their tone of voice and loudness while speaking, which is indicative of being monotone. Moreover, they stay in very close proximity to their clients (i.e., less than $1 \mathrm{~m}$ ) and are frontally oriented toward them (they mainly stand vis-à-vis their client without moving apart). As a consequence, this cluster is labeled as "adhesive statics".

All three kinds of nonverbal communication behaviors (i.e., kinesics - posture activity, paralanguage - front volume/consistency and pitch, and proxemics - face-toface interaction and proximity) contribute to the classification task. A more detailed analysis indicates that front volume and proximity are of particular importance.

The same steps of cluster analysis investigated nonverbal variables of customers. ${ }^{4}$ Interestingly, we find almost identical categorization results: a twocluster solution with cluster sizes 26 and 6 . Twenty-five salespeople are classified as "dynamic active" and all customers they served are also classified as such. Only one customer (pairing with an "adhesive-static"-salesperson) is classified as

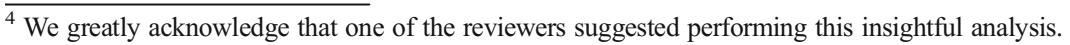


Table 2 Results of $k$-means cluster analysis and profiling of clusters

\begin{tabular}{|c|c|c|c|c|c|c|}
\hline $\begin{array}{l}\text { Nonverbal variables } \\
\text { (salespeople) }\end{array}$ & Total sample & \multicolumn{2}{|c|}{ Dynamic actives } & Adhesive statics & \multicolumn{2}{|l|}{$p$ level } \\
\hline Posture activity & 0.43 & \multicolumn{2}{|l|}{0.52} & 0.09 & \multicolumn{2}{|l|}{$<0.01$} \\
\hline Posture (front/back) & 0.59 & \multicolumn{2}{|l|}{0.54} & 0.76 & \multicolumn{2}{|l|}{ n.s. } \\
\hline Posture (left/right) & 0.27 & \multicolumn{2}{|l|}{0.28} & 0.25 & \multicolumn{2}{|l|}{ n.s. } \\
\hline Volume & 0.29 & \multicolumn{2}{|l|}{0.34} & 0.11 & \multicolumn{2}{|l|}{$<0.01$} \\
\hline Volume consistency & 0.52 & \multicolumn{2}{|l|}{0.44} & 0.79 & \multicolumn{2}{|l|}{$<0.01$} \\
\hline Pitch & 0.47 & \multicolumn{2}{|l|}{0.52} & 0.27 & \multicolumn{2}{|l|}{$<0.01$} \\
\hline Face-to-face & 0.13 & \multicolumn{2}{|l|}{0.08} & 0.33 & \multicolumn{2}{|l|}{$<0.01$} \\
\hline Proximity & 0.25 & \multicolumn{2}{|l|}{0.16} & 0.59 & \multicolumn{2}{|l|}{$<0.01$} \\
\hline $\begin{array}{l}\text { Nonverbal variables } \\
\text { (customers) }\end{array}$ & Total sample & \multicolumn{2}{|c|}{ Dynamic actives } & Adhesive statics & \multicolumn{2}{|l|}{$p$ level } \\
\hline Posture activity & 0.46 & \multicolumn{2}{|l|}{0.53} & 0.17 & \multicolumn{2}{|l|}{$<0.01$} \\
\hline Posture (front/back) & 0.66 & \multicolumn{2}{|l|}{0.61} & 0.88 & \multicolumn{2}{|l|}{0.02} \\
\hline Posture (left/right) & 0.60 & \multicolumn{2}{|l|}{0.64} & 0.49 & \multicolumn{2}{|l|}{ n.s. } \\
\hline Volume & 0.33 & \multicolumn{2}{|l|}{0.54} & 0.12 & \multicolumn{2}{|l|}{0.02} \\
\hline Volume consistency & 0.58 & \multicolumn{2}{|l|}{0.38} & 0.73 & \multicolumn{2}{|l|}{ n.s. } \\
\hline Pitch & 0.50 & \multicolumn{2}{|l|}{0.53} & 0.35 & \multicolumn{2}{|l|}{0.07} \\
\hline Face-to-face & 0.13 & \multicolumn{2}{|l|}{0.07} & 0.37 & $<0.01$ & \\
\hline Proximity & 0.25 & 0.16 & & 0.66 & $<0.01$ & \\
\hline & Profiling of $\mathrm{cl}$ & usters (sale & eople) & Profiling of cluste & ers (custom & \\
\hline Descriptives & Total & $\begin{array}{l}\text { Dynamic } \\
\text { actives }\end{array}$ & $\begin{array}{c}\text { Adhesive } \\
\text { statics }\end{array}$ & Total & $\begin{array}{l}\text { Dynamic } \\
\text { actives }\end{array}$ & $\begin{array}{c}\text { Adhesive } \\
\text { statics }\end{array}$ \\
\hline Cluster size & 32 & 25 & 7 & 32 & 26 & 6 \\
\hline Gender (females) & $63 \%$ & $68 \%$ & $43 \%$ & $75 \%$ & $73 \%$ & $83 \%$ \\
\hline Age (mean) in years & 34 & 31 & 47 & 36 & 34 & 41 \\
\hline Age (range) in years & $21-56$ & $21-49$ & $38-56$ & $18-71$ & $18-71$ & $22-67$ \\
\hline Purchase frequency & $53 \%$ & $68 \%$ & $0 \%$ & $53 \%$ & $65 \%$ & $0 \%$ \\
\hline $\begin{array}{l}\text { Median purchase } \\
\text { amount }\end{array}$ & $34.95 €$ & $110.00 €$ & $0.00 €$ & $34.95 €$ & $95.00 €$ & $0.00 €$ \\
\hline
\end{tabular}

"dynamic active". The middle panel of Table 2 demonstrates that customers executed quite similar nonverbal behaviors. This similarity can be explained by the fact that interaction partners show mirroring behaviors (Fatt 1998, Peterson 2005). Mirroring, or emulating nonverbal behaviors, occurs mainly unconsciously and establishes strong rapport among interaction partners. Moreover, research has revealed that "without the correct body language or paralinguistic cues customers are either dissatisfied or fail to develop the empathy with the provider" (Gabbott and Hogg 2000, p. 394).

The lower panel of Table 2 provides the profiling of the two clusters based on demographics and purchase behavior. As shown, the clusters do not differ largely for salespeople and customers. 


\subsubsection{Mediation analysis}

Figure 1 shows the conceptual model; in statistical terms, this is a mediation model with dynamic vs. static communication style as the independent variable (taken from the preceding classification procedure), perceived charisma as the mediator, and customer responses as the dependent variables. Hayes's (2013) PROCESS procedure, model 4, analyzed the data. Table 3 presents the statistical results.

Investigation of $\mathrm{H} 1$ (first panel of Table 3 ). There is a statistically significant impact of communication style on perceived charisma, i.e., the charisma of dynamic actives is on average perceived by 2.38 points (of a 7-point scale) better than the charisma of adhesive statics. The effect size of this relationship is considerable, i.e., .42. Thus, $H 1$ is supported.

Investigation of $\mathrm{H} 2$ (second panel of Table 3, total effects column). There is a positive, statistically significant impact of communication style on all three response variables which are based on customers' evaluations (attitude toward the salesperson-

Table 3 Results of mediation analysis

\begin{tabular}{|c|c|c|c|c|c|c|c|}
\hline \multirow{2}{*}{$\begin{array}{l}\text { Predictor } \\
\text { variables }\end{array}$} & \multicolumn{3}{|l|}{ Direct effects } & \multicolumn{2}{|c|}{ Indirect effects } & \multicolumn{2}{|c|}{ Total effects } \\
\hline & $\begin{array}{l}\text { Unstandardized } \\
\text { regression coefficient }\end{array}$ & \multicolumn{2}{|l|}{$p$ level } & & $\begin{array}{l}\text { Confidence } \\
\text { interval (a) }\end{array}$ & & $p$ level \\
\hline & \multicolumn{7}{|l|}{ Investigation of $\mathrm{H} 1$} \\
\hline & \multicolumn{7}{|c|}{ Response variable: perceived charisma } \\
\hline \multirow[t]{4}{*}{ Dynamic actives } & 2.38 & $<0.01$ & & & & & \\
\hline & $R^{2}=0.42$ & $F=21.84$ & $<0.01$ & & & & \\
\hline & \multicolumn{7}{|c|}{ Investigation of $\mathrm{H} 2$ and $\mathrm{H} 3$} \\
\hline & \multicolumn{7}{|c|}{ Response variable: attitude toward salesperson } \\
\hline Dynamic actives & -0.32 & n.s. & & 2.36 & {$[1.44 ; 3.10]$} & 2.04 & $<0.01$ \\
\hline \multirow[t]{3}{*}{ Per. charisma } & 0.99 & $<0.01$ & & & & & \\
\hline & $R^{2}=0.89$ & $F=114.20$ & $<0.01$ & $\kappa^{2}=0.73^{(b)}$ & & & \\
\hline & \multicolumn{7}{|c|}{ Response variable: perceived product quality } \\
\hline Dynamic actives & -0.41 & n.s. & & 1.90 & {$[1.07 ; 2.98]$} & 1.49 & $<0.01$ \\
\hline \multirow[t]{3}{*}{ Per. charisma } & 0.80 & $<0.01$ & & & & & \\
\hline & $R^{2}=0.75$ & $F=43.39$ & $<0.01$ & $\kappa^{2}=0.62$ & & & \\
\hline & \multicolumn{7}{|c|}{ Response variable: intention to recommend store } \\
\hline Dynamic actives & 0.11 & n.s. & & 2.63 & {$[1.57 ; 3.74]$} & 2.74 & $<0.01$ \\
\hline \multirow[t]{3}{*}{ Per. charisma } & 1.11 & $<0.01$ & & & & & \\
\hline & $R^{2}=0.90$ & $F=136.49$ & $<0.01$ & $\kappa^{2}=0.71$ & & & \\
\hline & \multicolumn{7}{|c|}{ Response variable: purchase (yes/no) ${ }^{(c)}$} \\
\hline Dynamic actives & 20.61 & & n.s. & 5.93 & {$[1.73 ; 23.29]$} & 22.96 & n.s. \\
\hline \multirow[t]{2}{*}{ Per. charisma } & 2.49 & & 0.05 & & & & \\
\hline & $R^{2}=0.76$ & $\chi^{2}=27.05$ & $<0.01$ & & & & \\
\hline
\end{tabular}

\footnotetext{
(a) Bias-corrected confidence intervals are based on 2000 bootstrap samples and a type I error of 5\%

(b) Effect size (Preacher and Kelley 2011)

(c) Logistic regression; Nagelkerke $R^{2}$ and Omnibus $\chi^{2}$ are reported
} 
2.04 points; perceived product quality -1.49 points; intention to recommend the store-2.74 points). Missing data variability for the adhesive statics cluster prevented reliable estimates for the purchase behavior variable. On the whole, $H 2$ is supported.

Investigation of H3 (second panel of Table 3, indirect effects column). There is a positive, statistically significant indirect (via perceived charisma) impact of communication style on all three response variables which are based on customers' evaluations (attitude toward the salesperson-2.36 points; perceived product quality -1.90 points; intention to recommend the store- -2.63 points). Table 3 also presents the corresponding bootstrap confidence intervals for a type I error of 5\% based on 2000 bootstrap samples and substantial effect sizes according to Preacher and Kelley's (2011) $\kappa^{2}$. At the same time, direct effects of communication styles are consistently not significant and, therefore, we find full mediation for all evaluative response variables. Thus, $H 3$ is supported.

\section{Discussion}

This field study introduced a new approach for measuring nonverbal communication across its components, kinesics, paralanguage, and proxemics, in a sales context. While data collection was quite elaborate, the results have face validity, are in accordance with extant literature, and yield various practical implications. First, we show that salespeople can enhance their charismatic appearance when using a more dynamic communication style, such as using variation in speech and loudness, in contrast to rather static, adhesive, and monotone communication. Moreover, findings reveal that a salesperson's charisma, as perceived by the customer, mediates the relationship between a salesperson's dynamic communication style and various customer responses. Thus, charisma was found to be an important driver of favorable customer responses. Additionally, this study confirms the claims of Pentland (2008) that this new tool is both an objective and reliable instrument for observing nonverbal communication behaviors and can also be used in marketing research and for training purposes. In sum, we show that sociometers can be employed reliably and conveniently for sales research and demonstrate that they have predictive validity. Further validation of the sociometric badges (i.e., by external measures of the salespeople) is recommended in future studies.

The device provides instant feedback to its wearer, which, in turn, delivers various managerial implications for sales executives, trainers, and store managers. In more detail, sociometric badges could reveal insights on how to interact with customers more effectively by employing these unobtrusive devices during sales trainings (i.e., role-plays) in a dyadic format. Moreover, the analysis of sales-pitches might provide additional insights on how to enhance a salesperson's appeal. In such a case, the sociometric badge is worn by the salespeople only and yields feedback on their performance. Alternatively, future research could investigate scenarios where either the customer or the salesperson is unaware of the device (i.e., mystery shopping). Besides applying sociometric badges in a sales context, further studies might be conducted in the health care or educational sector, as well as organizational settings such as negotiations or business meetings, or other forms of interaction.

This study is subject to limitations. We mention the relatively small sample size, which results from the empirical setting of a field study and cold canvassing of 
respondents. Moreover, further research might examine nonverbal communication behaviors across cultures and industries. Besides addressing these limitations, further research might investigate interaction patterns between customers and sales personnel by analyzing nonverbal communication over time.

Funding Information Open access funding provided by University of Vienna.

OpenAccess This article is distributed under the terms of the Creative Commons Attribution 4.0 International License (http://creativecommons.org/licenses/by/4.0/), which permits unrestricted use, distribution, and reproduction in any medium, provided you give appropriate credit to the original author(s) and the source, provide a link to the Creative Commons license, and indicate if changes were made.

Publisher's note Springer Nature remains neutral with regard to jurisdictional claims in published maps and institutional affiliations.

\section{References}

Antonakis, J., Fenley, M., \& Liechti, S. (2011). Can charisma be taught? Tests of two interventions. Academy of Management Learning and Education, 10, 374-396. https://doi.org/10.5465/amle.2010.0012.

Apple, W., Streeter, L. A., \& Krauss, R. M. (1979). Effects of pitch and speech rate on personal attributions. Journal of Personality and Social Psychology, 37, 715-727. https://doi.org/10.1037/0022-3514.37.5.715.

Arena, M. J., Pentland, S., \& Price, D. (2010). Honest signals - hard measures for social behavior. Organization Development Journal, 28, 11-20.

Bettinghaus, E. P., \& Cody, M. J. (1994). Persuasive communication. New York: Rinehart and Winston.

Burgoon, J. K., Birk, T., \& Pfau, M. (1990). Nonverbal behaviors, persuasion, and credibility. Human Communication Research, 17, 140-169. https://doi.org/10.1111/j.1468-2958.1990.tb00229.x.

Fatt, J. P. T. (1998). Nonverbal communication and business success. Management Research News, 21, 1-10.

Gabbott, M., \& Hogg, G. (2000). An empirical investigation of the impact of non-verbal communication on service evaluation. European Journal of Marketing, 34, 384-398. https://doi.org/10.1108 /03090560010311911.

Grewal, D., Monroe, K. B., \& Krishnan, R. (1998). The effects of price-comparison advertising on buyer's perceptions of acquisition value, transaction value, and behavioral intentions. Journal of Marketing, 62, 46-59. https://doi.org/10.2307/1252160.

Guerrero, L., \& Floyd, K. (2006). Nonverbal communication in close relationships. Mahwah: Lawrence Erlbaum Associates.

Hall, E. T., \& Hall, M. R. (1977). Nonverbal communication for educators. Theory Into Practice, 16, 141-144. https://doi.org/10.1080/00405847709542689.

Hayes, A. F. (2013). Introduction to mediation, moderation, and conditional process analysis: a regressionbased approach. New York: The Guilford Press.

Heide, F. J. (2013). 'Easy to sense but hard to define': charismatic nonverbal communication and the psychotherapist. Journal of Psychotherapy Integration, 23, 305-319. https://doi.org/10.1037/a0032481.

Holladay, S. J., \& Coombs, T. W. (1994). Speaking of visions and visions being spoken: an exploration of the effects of content and delivery on perceptions of leader charisma. Management Communication Quarterly, 8, 165-189. https://doi.org/10.1177/0893318994008002002.

Khatri, N., Ng, H. A., \& Lee, T. (2001). The distinction between charisma and vision: an empirical study. Asia Pacific Journal of Management, 18, 373-393. https://oi.org/10.1023/A:1010653929261.

Kim, T., McFee, E., Olguin-Olguin, D., Waber, B., \& Pentland, A. S. (2012). Sociometric badges: using sensor technology to capture new forms of collaboration. Journal of Organizational Behavior, 33, 412-427. https://doi.org/10.1002/job.1776.

Kirkpatrick, S. A., \& Locke, E. A. (1996). Direct and indirect effects of three core charismatic leadership components on performance and attitudes. Journal of Applied Psychology, 81, 36-51. https://doi. org/10.1037/0021-9010.81.1.36.

Leigh, T. W., \& Summers, J. O. (2002). An initial evaluation of industrial buyers impressions of salespersons' nonverbal cues. Journal of Personal Selling and Sales Management, 22, 41-53. https://doi.org/10.1080 /08853134.2002.10754292. 
MacKenzie, S., \& Lutz, R. (1989). An empirical examination of the structural antecedents of attitude toward the ad in an advertising pretesting context. Journal of Marketing, 53, 48-65. https://doi.org/10.2307 $/ 1251413$.

Maxham, J. G., \& Netemeyer, R. G. (2002). Modeling customer perceptions of complaint handling over time: the effects of perceived justice on satisfaction and intent. Journal of Retailing, 78, 239-252. https://doi. org/10.1016/S0022-4359(02)00100-8.

Mehrabian, A. (1969). Significance of posture and position in the communication of attitude and status relationships. Psychological Bulletin, 71, 359-372. https://doi.org/10.1037/h0027349.

Mehrabian, A., \& Williams, M. (1969). Nonverbal concomitants of perceived and intended persuasiveness. Journal of Personality and Social Psychology, 13, 37-58. https://doi.org/10.1037/h0027993.

Olguin-Olguin, D., \& Pentland, A. (2008). Social sensors for automatic data collection. Toronto: Proceedings of the Fourteenth Americas Conference on Information Systems.

Olguin-Olguin, D., Paradiso, J., \& Pentland, A. (2006). Wearable communicator badge: designing a new platform for revealing organizational dynamics. Proceedings of the 10th International Symposium on Wearable Computers, Montreaux, Switzerland.

Olguin-Olguin, D., Gloor, P. A., \& Pentland, A. (2009). Capturing individual and group behavior with wearable sensors. Stanford: AAAI Spring Symposium on Human Behavior Modeling.

Pauser, S., Wagner, U., \& Ebster, C. (2018). An investigation of salespeople's nonverbal behaviors and their effect on charismatic appearance and favorable consumer responses. Journal of Personal Selling and Sales Management, 38, 344-369. https://doi.org/10.1080/08853134.2018.1480383.

Pentland, A. (2008). Honest signals: how they shape our world. Massachusetts: MIT Press.

Peterson, R. T. (2005). An examination of the relative effectiveness of training in nonverbal communication: personal selling implications. Journal of Marketing Education, 27, 143-150. https://doi.org/10.1177 /0273475305276627.

Peterson, R. A., Cannito, M. P., \& Brown, S. P. (1995). An exploratory investigation of voice characteristics and selling effectiveness. Journal of Personal Selling and Sales Management, 15, 1-15.

Preacher, K. J., \& Kelley, K. (2011). Effect size measures for mediation models: quantitative strategies for communicating indirect effects. Psychological Methods, 16, 93-115. https://doi.org/10.1037/a0022658.

Rentz, J. O., Shepherd, C. D., Tashchian, A., Dabholkar, P. A., \& Ladd, R. T. (2002). A measure of selling skill: scale development and validation. Journal of Personal Selling and Sales Management, 22, 13-21. https://doi.org/10.1080/08853134.2002.10754289.

Stewart, D. W., Hecker, S., \& Graham, J. L. (1987). It's more than what you say: assessing the influence of nonverbal communication in marketing. Psychology and Marketing, 4, 303-322.

Sy, T., Choi, J. N., \& Johnson, S. K. (2013). Reciprocal interactions between group perceptions of leader charisma and group mood through mood contagion. Leadership Quarterly, 24, 463-476. https://doi. org/10.1016/j.leaqua.2013.02.002.

Vercic, A. T., \& Vercic, D. (2011). Generic charisma - conceptualization and measurement. Public Relations Review, 37, 12-19. https://doi.org/10.1016/j.pubrev.2010.12.002.

Williams, K. C., Spiro, R. L., \& Fine, L. M. (1990). The customer-salesperson dyad: an interaction/ communication model and review. Journal of Personal Selling and Sales Management, 10, $29-43$. 